\section{SAT0052 COLOMBIAN GUIDELINES FOR THE TREATMENT OF HIP, KNEE AND HAND OSTEOARTHRITIS}

E Diaz, JL Rueda-Cifuentes, HL Gonzalez-Medina, MA Chalem-Iglesias, FE Rondon-Reyes, JY Forero-Muñoz, GJ Ramirez-Manrique, LO Ramirez-Uribe, LJ Pinto-Molina, RJ Sierra-Salas. Rheumatology, Colombian Association of Rheumatology, Bogota, Colombia

\subsection{6/annrheumdis-2001.427}

Background The highest burden of rheumatic disease in Colombia according to the Ministry of Health is due to Osteoarthritis (OA) and Rheumatoid Arthritis (RA). Currently we don't have guidelines for the treatment of OA in our country.

Objectives To propose recommendations for treatment (medical and surgical) of hip, knee and hand OA based on both Evidence Based Medicine (EBM) and expert consensus approach.

Methods A task force of experts in Clinical Epidemiology and in OA research and management was created. The first stage was to assist a two-day course of guideline methodology. The second stage was the selection of treatment modalities and principal clinical questions to be considered. The third stage was a systematic literature review that permitted the ranking of the recommendations from A (based on results of meta-analyses) to $\mathrm{E}$ (negative recommendations based on results of meta-analyses). The final stage was recopilation and review of the consensus by an internal/external pair.

Results Different non-pharmacological and surgical modalities were evaluated.

Medical: Acetaminophen, NSAIDS and COXIBS were similar in efficacy to relieve pain (A). Gastrointestinal safety improves with COXIBS rather than the comparators (A). Hialuronate acid, glucosamine sulfate and NSAIDS were similar in efficacy to relieve pain (A-B).

Alternative: Yoga and acupuncture lessened pain and improved functional capacity (B-C).

Surgery: There is no recommendation for knee and hip artroplasty.

Conclusion The recommendations of this task force (1) the best evidence is in the treatment of pain; (2) currently there is no evidence for drugs modified disease; (3) certain alternative medicines are useful as coadyuvants and (4) this consensus is the base for new research.

\section{SAT0053 EFFICACY AND SAFETY OF SYNVISC IN SEVERE KNEE OSTEOARTHRITIS (OA): EXPERIENCE FROM A LARGE COHORT OF PATIENTS FOLLOWED IN PRIVATE RHEUMATOLOGICAL PRACTICE}

${ }^{1} \mathrm{~A}$ Wulwik, ${ }^{2} \mathrm{~S}$ Bertocci, ${ }^{3} \mathrm{~V}$ Raude-Leroy, ${ }^{3} \mathrm{PL}$ Lleu. ${ }^{1}$ Rheumatology, Private Office, Paris, France; ${ }^{2}$ Medical Department, Genzyme Biosurgery, Paris, France; ${ }^{3}$ Medical Department, Boehringer-Ingelheim, Reims, France

\subsection{6/annrheumdis-2001.428}

\section{Background}

Objectives It is demonstrated that Synvisc ${ }^{\circledR}$ (S) (3 intra-articular injections at 1 week apart) improved algofunctional status of patients with knee OA. In this cohort study, the efficacy of S. was followed for up to 2 years in a specific population of patients with severe knee OA, confirmed clinically and radiologically. One half of those patients were candidates for a total knee replacement.

Methods In all patients treated with S. between June 1998 and September 1999, demographic data and medical history were recorded. Following S. course, a rheumatological evaluation was performed to assess improvement and local safety. Then, a longterm follow-up was performed in May 2000, all patients completing a questionnaire recording their clinical status, global satisfaction, tolerance of $\mathrm{S}$. and concomitant therapies consumption. Due to methodology of this study, patients? long-term follow-up ranked from 9 to 24 (mean $=15.5$ ) months.

Results Out of 117 patients treated, 81 (70\%) completed the follow-up questionnaire.

Baseline characteristics of those 81 patients are as follow:

- demographic data: mean age $=71$ years; female $=57 \%$; BMI $=27.5 \mathrm{~kg} / \mathrm{m}^{2}$

- medical history: mean disease duration $=8$ years; femorotibial knee OA: 97\% (isolated: 33\% or associated with femoro-patelar knee OA: 64\%); chondrocalcinose: 19\%

At baseline, 54\% of patients had a ?severe? and 42\% a ?very severe? knee OA according to physician. Nineteen patients $(23 \%)$ were treated by S. in both knees and 15 (19\%) received two courses of $S$. in the same knee (mean time between these two courses $=11$ months).

A clinically significant improvement (moderate, important or very important) was observed by the physician after $77 \%$ of $\mathrm{S}$. courses, while this treatment was followed by transient local adverse events (pain, swelling) after only $15 \%$ of S. courses (3 IA injections).

The analysis of patients? questionnaires showed that $49 \%$ reported a ?severe? pain and 22\% a ?very severe? pain before treatment with $\mathrm{S}$. The treatment was considered as globally satisfactory by $63 \%$ of patients, the main symptoms improved being pain on movement (56\% of patients) and nocturnal pain $(52 \%)$. Out of daily living? activities, ascending and descending stairs were improved in $51 \%$ and $46 \%$ of patients respectively. Most patients (53\%) improved their maximum distance walked and $22 \%$ resumed their leisure activities. Moreover 90\% of them reported a good tolerance of S. and 47\% decreased their analgesics and NSAIDs consumption.

Conclusion This study demonstrates the interest of high molecular viscosupplementation with Synvisc ${ }^{\circledR}$ in the management of severe knee OA patients. Of special interest, 32 patients $(82 \%)$ out of 39 candidates for total knee replacement at baseline, were able to delay this surgical treatment.

\section{SAT0054 CLINICAL EFFICACY AND SAFETY OF LOXOPROFEN SODIUM IN THE TREATMENT OF GONARTHROSIS}

R Lederman, S Guimarães, JF Verztman. Rheumatology, Hospital Dos Servidores Do Estado, Rio de Janeiro, Brazil

\subsection{6/annrheumdis-2001.429}

Background There have been advances in the understanding of osteoarthritis, but current treatment is purely to control symptoms. NSAIDs drugs remain the most commonly used agents, despite their potential for GI adverse events. Loxoprofen sodium, a NSAID prodrug from phenylpropionic class, synthesised by Sankyo Co., is claimed to have lesser GI and renal toxicity, probably due to its prodrug characteristics and to intermediate COX-2 selectivity. A large clinical experience in oriental people is available, but its use in occidental people is scarce.

Objectives The objective of this double blind, randomised, parallel, controlled trial was compare the efficacy and safety of Loxoprofen with that of diclofenac in the treatment of gonarthrosis. 
Methods Ambulatory patients with gonarthrosis grade 2 or 3 of Kellgren and Lawrence classification, 30 ? 60 years old, with body mass index $(\mathrm{BMI})<30 \mathrm{~kg} / \mathrm{m}^{2}$ were admitted to the study after comply with inclusion and exclusion criteria. After have been given their informed consent, patients were randomly allocated, in a double-blind way, into treatment groups - Loxoprofen $60 \mathrm{mg}$ t.i.d. or diclofenac $50 \mathrm{mg}$ t.i.d. Duration of treatment was four weeks, and patients were evaluated at pretreatment and every two weeks during therapy for: overall severity of symptoms; pain at rest, on pressure, on movement and nocturnal through a visual analogue scale (VAS); swelling of knee; functional disability; global improvement; side-effects. Laboratory tests were performed in all patients, pre and post treatment.

Results A total of 60 patients was treated ? 30 in each group. There was no significant difference between the groups; $87 \%$ of patients were $>51$ years old. Mean disease duration was $2655 \pm$ 2168 days in LOX and $2086 \pm 1333$ days in DIC (n.s.). 23 patients in LOX and 24 in DIC reported previous treatments with NSAIDs, being diclofenac the most frequent prescribed drug. All parameters evaluated showed statistically significant improvements compared with baseline ( $p<0.0001$ ? chi square) with both treatments; there were no statistically significance differences between treatments groups. GI adverse events occurred in 3 patients $(10 \%)$ of LOX and in $12(40 \%)$ of $\mathrm{DIC}(\mathrm{p}<0.01)$. Epigastralgia was the most prevalent GI event reported (1 in LOX; 7 in DIC). One serious adverse event ? enterorrhagia ? was reported in the diclofenac group, with discontinuation of treatment. Tolerability assessments were classified as both very good and good in 90\% in LOX and in 79\% in DIC ( $\mathrm{p}<0.05$ ). One patient in LOX discontinued therapy due to worsening of the disease, and 5 in DIC ? 4 due to adverse events and 1 worsening of the disease. About $80 \%$ of overall assessment were classified, by investigator and patient, as either very good or good in Loxoprofen group and 70\% in the diclofenac group (n. s.).

Conclusion Loxoprofen $60 \mathrm{mg}$, t.i.d., showed good efficacy accompanied by excellent tolerability and safety in gonarthrosis, which was superior to that of an established NSAID, diclofenac $50 \mathrm{mg}$, t.i.d.

\section{SAT0055 EFFECT OF ROFECOXIB, CELECOXIB, AND NAPROXEN ON BLOOD PRESSURE AND URINARY SODIUM EXCRETION IN ELDERLY VOLUNTEERS}

${ }^{1} \mathrm{Jl}$ Schwartz, ${ }^{2} \mathrm{MP}$ Malice, ${ }^{3} \mathrm{KC}$ Lasseter, ${ }^{4} \mathrm{~GB}$ Holmes, ${ }^{1} \mathrm{KM}$ Gottesdiener, ${ }^{5} \mathrm{~K}$ Brune. ${ }^{1}$ Clinical Pharmacology, Merck \& Co, Inc., Rahway; ${ }^{2}$ Biostatistics, Merck \& Co, Inc., Brussels, Belgium; ${ }^{3}$ Clinical Research, Clinical Pharmacology Associates, Miami; ${ }^{4}$ Clinical Research, SFBC-International, Miami, USA; ${ }^{5}$ Clinical Pharmacology, University Erlangen, Erlangen, Germany

\subsection{6/annrheumdis-2001.430}

Background Nonsteroidal anti-inflammatory drugs (NSAIDs) can affect sodium reabsorption by decreasing the synthesis of renal prostaglandins. Since COX-2 is constitutively expressed in the kidney, it is hypothesised that the effects of COX-2 inhibitors on sodium handling would be similar to non-selective NSAIDs. It is hypothesised moreover that the effects of the two COX-2 inhibitors on sodium handling would be similar.

Objectives This study evaluated the effects of two COX-2 inhibitors [rofecoxib, $25 \mathrm{mg}$ QD and celecoxib, $200 \mathrm{mg}$ BID], a nonselective NSAID [naproxen, $500 \mathrm{mg}$ BID], and placebo on blood pressure (BP) and urinary sodium excretion during a 2-week inhouse administration.
Methods 67 healthy elderly (60 to 80 years) subjects participated in a double-blind, placebo-controlled, parallel-group study. Subjects received a weight-maintaining isocaloric diet $(200 \mathrm{mEq}$ sodium, $0.8 \mathrm{~g} / \mathrm{kg}$ protein, 80 to $120 \mathrm{mEq}$ potassium daily), beginning 8-13 days prior to the first dose of study drug. After attaining sodium balance [based on stable weight (within $0.5 \mathrm{~kg}$ ) and 24-hour urinary sodium between 180 to $220 \mathrm{mEq}$ on 2 consecutive days], subjects were randomised to treatment. Daily 24hour urine collections were obtained. Daily BP measurements were taken at $8 \mathrm{AM}$ and $8 \mathrm{PM}$, and more often (8 AM, Noon, 4 PM, and 8 PM) on Days -1, 1, 7, and 14.

Results Least-Squares mean changes from baseline (SE) for average daily BP on Day 14 (prespecified primary endpoint for BP) are shown in the Table 1 below. There was no significant difference between the active treatment groups in daily average sodium excretion during the first 3 days or over 2 weeks of treatment $(p>0.05)$. No incidence of peripheral oedema occurred during the 2 week treatment. Two subjects experienced elevated systolic BP during the course of the trial (one on each COX-2 inhibitor).

\begin{tabular}{lllll} 
Abstract SAT0055 & Table 1 \\
& Rofecoxib & Celecoxib & Naproxen & Placebo \\
& $\mathrm{N}=17$ & $\mathrm{~N}=17$ & $\mathrm{~N}=17$ & $\mathrm{~N}=16$ \\
\hline Systolic BP(mm Hg) & $3.4(2.0)$ & $4.3(2.0)$ & $3.1(2.0)$ & $-1.4(2.0)$ \\
Diastolic BP(mm Hg) & $0.3(1.0)$ & $0.8(1.0)$ & $-0.4(1.0)$ & $-1.4(1.0)$ \\
\hline
\end{tabular}

Least-Squares Mean Changes from Baseline (SE) for Average Daily BP on Day 14.

Conclusion These results, obtained under well-controlled conditions for two weeks, suggest that the COX-2 selective agents, rofecoxib and celecoxib, have similar effects on BP and urinary sodium excretion; their effect is similar also to that of non-selective NSAIDs.

\section{SAT0056 BISPHOSPHONATE MODULATES ECTOPIC BONE FORMATION AFTER HIP ARTHROPLASTY -WITH JAPANESE CASES-}

Y Yutani, Y Yamano. Department of Orthopaedic Surgery, Osaka City University Medical School, Osaka, Japan

\subsection{6/annrheumdis-2001.431}

Background Ectopic bone formation has been reported as the complication after hip arthroplasty, at the time of paralysis of extremities and cerebral trauma, and in the presence of congenital diseases such as progressive ostosis. Bisphosphonates have been developed as the agent for improving bone metabolism, and are currently used as 1) a derivative in making a radioisotope diagnosis, 2) an inhibitor of bone resorption, 3) a preventive agent for ossification, and 4) an inhibitor of calculus formation in dentistry.

Objectives We have investigated the therapeutic effects of etidronate disodium (EHDP) as a bisphosphonate on ectopic bone formation developing after hip arthroplasty and the indications for administration of EHDP. The patients who had received implant arthroplasty 8 years ago were clinically evaluated, and the influence of EHDP on the prostheses was investigated.

Methods The subjects were the patients who had undergone total hip replacement or hip prosthesis replacement. They consisted of 40 women, and the ages at the time of operation 